\title{
Widespread distribution of Plasmodium vivax malaria in Mauritania on the interface of the Maghreb and West Africa
}

\author{
Hampâté Ba ${ }^{*}$, Craig W. Duffy², Ambroise D. Ahouidi ${ }^{3}$ Yacine Boubou Deh', Mamadou Yero Diallo',
} Abderahmane Tandia ${ }^{1}$ and David J. Conway ${ }^{2^{*}}$

\begin{abstract}
Background: Plasmodium vivax is very rarely seen in West Africa, although specific detection methods are not widely applied in the region, and it is now considered to be absent from North Africa. However, this parasite species has recently been reported to account for most malaria cases in Nouakchott, the capital of Mauritania, which is a large country at the interface of sub-Saharan West Africa and the Maghreb region in northwest Africa.

Methods: To determine the distribution of malaria parasite species throughout Mauritania, malaria cases were sampled in 2012 and 2013 from health facilities in 12 different areas. These sampling sites were located in eight major administrative regions of the country, within different parts of the Sahara and Sahel zones. Blood spots from fingerprick samples of malaria cases were processed to identify parasite DNA by species-specific PCR.

Results: Out of 472 malaria cases examined, 163 (34.5\%) had P. vivax alone, 296 (62.7\%) Plasmodium falciparum alone, and 13 (2.8\%) had mixed P. falciparum and P. vivax infection. All cases were negative for Plasmodium malariae and Plasmodium ovale. The parasite species distribution showed a broad spectrum, P. vivax being detected at six of the different sites, in five of the country's major administrative regions (Tiris Zemmour, Tagant, Brakna, Assaba, and the capital Nouakchott). Most cases in Nouakchott were due to P. vivax, although proportions vary significantly among different health facilities in the city. In the northern town of Zouérat, all cases were due to $P$. vivax, whereas almost all cases in the south of the country were due to P. falciparum. All P. vivax cases tested were Duffy blood group positive.

Conclusions: It is important that $P$. vivax is recognized to be a widespread cause of malaria in Mauritania, occurring in diverse regions. This should be noted by the World Health Organization, as it has significant implications for diagnosis, treatment and control of malaria in the northwestern part of Africa.
\end{abstract}

Keywords: Plasmodium vivax, Africa, Malaria, Endemic, Duffy positive

\section{Background}

Most malaria cases in Africa are caused by Plasmodium falciparum [1], with a relatively small proportion attributable to Plasmodium malariae or Plasmodium ovale, while Plasmodium vivax is known to occur in only some areas of the continent $[2,3]$. Following scale-up of

\footnotetext{
*Correspondence: hampateba2001@yahoo.fr; david.conway@lshtm.ac.uk ${ }^{1}$ Institut National de Recherches en Santé Publique (INRSP), Nouakchott, Mauritania

${ }^{2}$ Department of Pathogen Molecular Biology, London School of Hygiene and Tropical Medicine, London, UK

Full list of author information is available at the end of the article
}

prevention and treatment, the incidence of malaria has significantly declined in some areas, contributing to a reduction in overall mortality $[4,5]$. Although most of West Africa still has a high malaria burden, numbers of cases have markedly declined near the northwestern end of the endemic distribution [1,6,7]. More studies are needed in areas closer to the edge of endemicity, where seasonal transmission is normally very limited.

The country of Mauritania is at the extreme northwestern limit of malaria distribution in Africa. It has a population of approximately 3.5 million people, and covers a large area of 1,030,700 sq km², lying between 15 and $27^{\circ} \mathrm{N}$ 
latitude, and 5 and $17^{\circ} \mathrm{W}$ longitude. Malaria is considered to be the third most common cause of clinical presentation to health facilities in the country. Although a large part of the territory is Saharan desert, malaria is most common in areas of Sahel in the south of the country, and has been increasingly seen in Nouakchott, the capital city that contains approximately $25 \%$ of the country's inhabitants [8-10]. Recent reports indicate that $P$. vivax is more commonly seen than $P$. falciparum in patients with malaria in Nouakchott [9-12]. This represents an apparently unique epidemiological situation, as $P$. vivax has been very rarely or never seen at most other sites in West Africa [2, 3, 13-15]. One factor contributing to this is that most inhabitants in Nouakchott are ethnically identified as white Maures, who are generally positive for the Duffy antigen erythrocyte receptor for $P$. vivax, which is rare among other West African ethnic groups living mostly in the south of the country [16]. A second factor is that local breeding of the mosquito vector Anopheles arabiensis has been facilitated by surface water environments, created by loosely regulated urbanization over recent decades in an area that was originally desert [12].

Outside of the capital Nouackchott, the limited slide microscopy surveys conducted historically have indicated that almost all malaria cases are due to $P$. falciparum, apart from occasional cases reportedly being due to $P$. malariae and $P$. ovale [8]. $P$. vivax has not been clearly described at other sites, except for a few infections detected in 2009 and 2010 in the Hodh El Gharbi region in the south of the country [17], although it has been suspected elsewhere. As there have been few recent surveys, and identification of species by slide microscopy is often unreliable, a broad survey using molecular methods for species identification is needed. In this study, the distribution of parasite species in malaria cases was surveyed by sampling from health facilities at diverse sites throughout Mauritania.

\section{Methods}

Patients with malaria were sampled from among those attending 14 health facilities at 12 different geographical sites in eight administrative regions of Mauritania in 2012 and 2013 (Fig. 1). Three of the facilities were within the capital city Nouakchott: the National Hospital Centre, Cheikh Zayed Hospital Centre and Teyarett Health Centre, the first of which serves a broad population of mixed ethnicity, while the other two serve areas predominantly inhabited by white Maures. The large urban area of Nouakchott typically receives only 50 to $100 \mathrm{~mm}$ annual rainfall but has a large supply of piped water from the south of the country. One of the other sites sampled was far outside of the known malaria-endemic area, in the mining town of Zouérat (Tiris Zemmour Region) in the north of the country, which usually receives less than $50 \mathrm{~mm}$ of rain annually. The remaining nine health facilities were in different towns and villages throughout ecologically diverse parts of the country known to be endemic for malaria: Boghé (Brakna Region) in the Senegal River valley generally receives between 200 and $300 \mathrm{~mm}$ annual rainfall; Sélibaby and Ould Yenge (Guidimakha Region) within $100 \mathrm{~km}$ of the Senegal River valley receive between 300 and $600 \mathrm{~mm}$ annual rainfall; Aioun and Kobenni (Hodh El Garbi Region), Timbédra and Néma (Hodh El Chargi Region), and Kiffa (Assaba Region) are in a semi-arid zone where average rainfall varies between approximately 100 and $300 \mathrm{~mm}$; N'beika and Tidjikja (Tagant Region), are in an arid zone which usually receives only between 50 and $200 \mathrm{~mm}$ of rain annually (Fig. 1). The limited and variable annual rainfall in Mauritania mostly occurs between July and October, leading to seasonal malaria, so cases were sampled between August and December in each year.

Patients were diagnosed with uncomplicated clinical malaria by local health facility staff on the basis of clinical signs including the presence of fever, supported by positive rapid diagnostic tests detecting circulating malaria parasite lactate dehydrogenase (OPTIMAL-IT ${ }^{\mathrm{TM}}$ kits incorporating two different antibodies that are, respectively, $P$. falciparum species-specific and broadly Plasmodium-specific). Tests that are negative for P. falciparum but positive for Plasmodium are routinely considered to be likely due to either $P$. malariae, $P$. ovale, or $P$. vivax, although resolution of these alternative species is not done at diagnosis in most health facilities. All cases analysed were local residents who did not report having travelled within the previous 2 weeks, and who were invited to provide finger-prick blood samples. These were collected on filter paper and air-dried prior to storage with desiccant in sealed polythene bags. All samples were obtained with informed consent from patients, and guardians of patients who were under 18 years of age. Regardless of inclusion in the study, patients were treated at the health facilities with artemisinin combination therapy. Current recommendations of the National Malaria Control Programme are for first-line treatment combination of artesunate and amodiaquine, and second-line treatment option of artemether and lumefantrine, with primaquine being added in the case of confirmed $P$. vivax infection. The study was approved by ethics committees of the Ministry of Health of Mauritania and the London School of Hygiene and Tropical Medicine.

DNA was extracted from filter paper blood spots using QIAmp DNA Minikits (Qiagen, Valencia, CA, USA). Species-specific identification of malaria parasites by nested PCR was performed using a published method [18], with a first round of Plasmodium genus-specific 
a

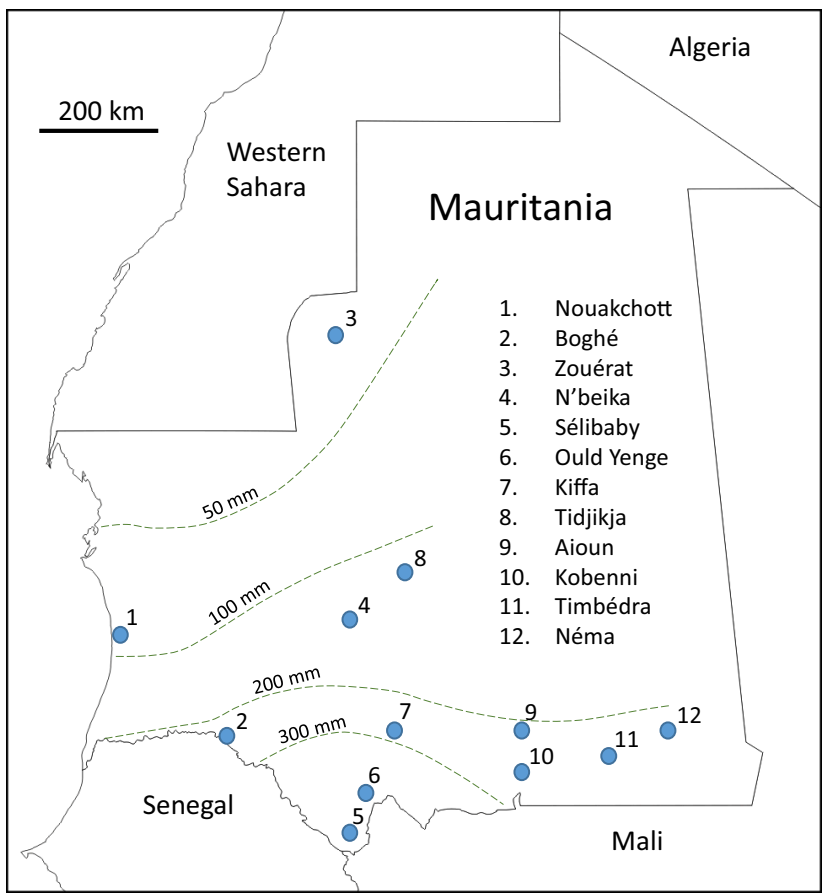

b
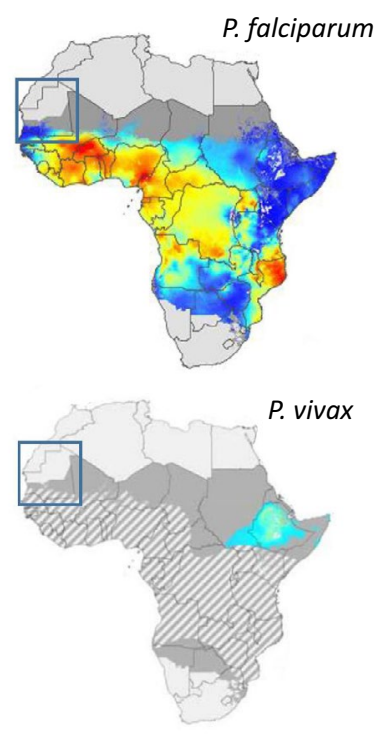

Fig. 1 Map of Mauritania showing the locations of the sampling sites in relation to average annual rainfall and previously known areas of malaria endemicity. a Malaria patients were sampled from 12 locations in Mauritania. In the capital city Nouakchott (Location 1) sampling was conducted from three hospitals: Health Centre of Teyarett, Cheikh Zayed Hospital Center, and the National Hospital Centre. Sampling was conducted from single facilities in each of the other 11 locations: hospitals in Sélibaby, Aioun, Néma and Zouérat, and health centres in each of the other locations. Malaria parasite species were determined from 472 patients in total (numbers from each location are given in Table 1). The approximate mean annual rainfall in millilitres in different areas is indicated by isohyets shown as dashed lines. $\mathbf{b}$. Inset rectangles indicate the position of the study area map on previously published maps of malaria parasite distribution in Africa $[1,3]$. Estimated endemic distributions of $P$. falciparum and $P$. vivax in 2010 are indicated by coloured shading (blue indicating low prevalence, yellow and red indicating higher prevalences). Grey shading indicates where sporadic transmission is considered possible without endemic maintenance. In the lower map the diagonal shading indicates where the majority of the population has the Duffy-negative blood group phenotype

PCR followed by species-specific amplification using primers to detect $P$. falciparum, P. vivax, P. malariae, and $P$. ovale. Products were separated electrophoretically on $1 \%$ agarose gels, stained with ethidium bromide and visualized using ultraviolet trans-illumination for photography and scoring. Positive and negative controls were included in all assays, with DNA from different malaria species kindly provided by Colin Sutherland from the UK Malaria Reference Laboratory.

A proportion of individuals sampled were genotyped to test for Duffy blood group negativity, based on the GATA-1 gene promoter allele that leads to null expression in West African populations, using a previously published protocol [19].

\section{Results}

Overall, 472 patients sampled had malaria parasites detected by Plasmodium genus-specific as well as species-specific PCR analyses. Of these, 296 (62.7\%) had
P. falciparum alone, 163 (34.5\%) P. vivax alone, and 13 (2.8\%) had mixed $P$. falciparum and $P$. vivax infections. None of the samples was positive for $P$. ovale or P. malariae. Apart from Nouakchott, in which infections were already known to occur, P. vivax is described here for the first time from five widely separated sites in four other administrative regions of Mauritania (Tiris Zemmour, Tagant, Brakna, and Assaba). The proportions of malaria cases with $P$. vivax and $P$. falciparum showed extreme variation among the different sites (Table 1). This ranged from a situation at six sites in the southeast of the country at which all cases detected were P. falciparum, through to the opposite extreme at Zouérat in the north of the country at which all cases were $P$. vivax. Both malaria parasite species were present at the remaining sites (Fig. 2).

In the capital Nouakchott, $P$. vivax was more common than P. falciparum in both 2012 and 2013. Overall, there was no significant difference between the 2 years in the relative proportion of the two parasite species. However, 
Table 1 Proportions of $P$. vivax and $P$. falciparum infections detected in malaria cases sampled from 12 different areas in Mauritania

\begin{tabular}{|c|c|c|c|c|c|}
\hline $\begin{array}{l}\text { Location and year } \\
\text { of sampling }\end{array}$ & $\begin{array}{l}\text { Number } \\
\text { positive }\end{array}$ & $\begin{array}{l}\text { P. vivax } \\
\text { alone }\end{array}$ & $\begin{array}{l}\text { P. falciparum } \\
\text { alone }\end{array}$ & $\begin{array}{l}P . \text { vivax and } \\
P . \text { falciparum } \\
\text { mixed }\end{array}$ & $\begin{array}{l}\text { Proportion of } \\
\text { P. vivax } \\
(\mathrm{Pv} /[\mathrm{Pv}+P f])^{\mathrm{a}}\end{array}$ \\
\hline \multicolumn{6}{|l|}{2012} \\
\hline Aioun & 30 & 0 & $30(100 \%)$ & 0 & 0.00 \\
\hline Boghé & 8 & 1 (13\%) & 7 (88 \%) & 0 & 0.13 \\
\hline Kobenni & 131 & 0 & 131 (100\%) & 0 & 0.00 \\
\hline N'beika & 6 & $4(67 \%)$ & $1(17 \%)$ & $1(17 \%)$ & 0.71 \\
\hline Tidjikja & 3 & 1 & 2 & 0 & 0.33 \\
\hline Timbédra & 17 & 0 & $17(100 \%)$ & 0 & 0.00 \\
\hline Nouakchott & 96 & 65 (68 \%) & $20(21 \%)$ & $11(11 \%)$ & 0.73 \\
\hline \multicolumn{6}{|l|}{2013} \\
\hline Sélibaby & 29 & 0 & $29(100 \%)$ & 0 & 0.00 \\
\hline Kiffa & 9 & $2(22 \%)$ & 7 (78\%) & 0 & 0.22 \\
\hline Ould Yenge & 14 & 0 & 14 (100\%) & 0 & 0.00 \\
\hline Zouérat & 25 & 25 (100\%) & 0 & 0 & 1.00 \\
\hline Néma & 24 & 0 & $24(100 \%)$ & 0 & 0.00 \\
\hline Nouakchott & 80 & 65 (81\%) & 14 (18\%) & $1(1 \%)$ & 0.81 \\
\hline
\end{tabular}

Individual locations are shown on Fig. 1. Samples from Nouakchott were from three different health facilities, and proportions of species at each of these are shown in Table 2

${ }^{a}$ Relative proportions of each species at each site are estimated by counting numbers of infections with each species, with each being counted separately from mixed species infections

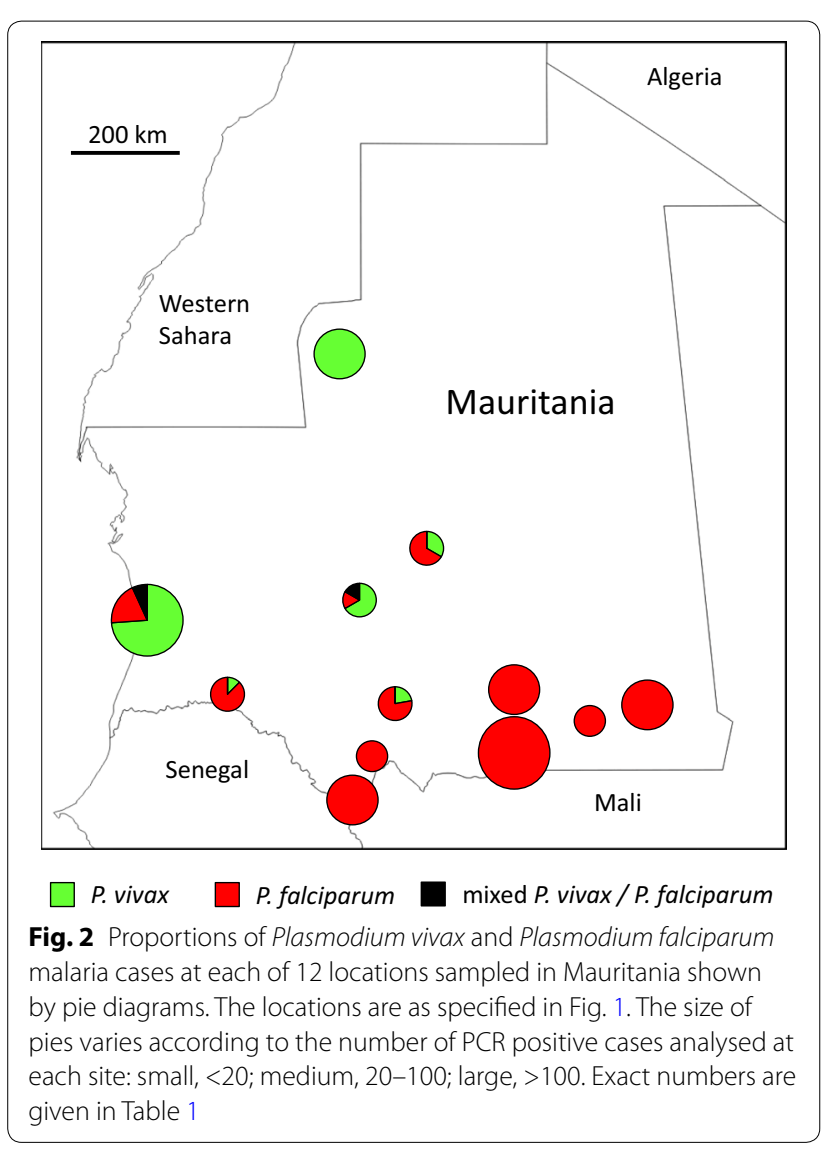

within each year there were differences in the proportions of species between the different health facilities sampled in Nouakchott (Table 2). At Teyarett Health Centre in both years, most malaria cases were caused by $P$. vivax, whereas in the other two hospitals sampled separately in the respective years there were more equal proportions of both P. vivax and P. falciparum. In 2012, $85 \%(49 / 53)$ of cases sampled from Teyarett Health Centre had P. vivax alone, in contrast with $37 \%(16 / 43)$ at the National Hospital Centre (Fisher's Exact $\mathrm{P}<0.0001$ ). In 2013, $85 \%(62 / 73)$ of cases sampled from Teyarett Health Centre had P. vivax alone, in contrast with $43 \%$ $(3 / 7)$ at the Cheikh Zayed Hospital Centre (Fisher's Exact $\mathrm{P}=0.013$ ).

Duffy promoter genotyping of $82 P$. vivax positive cases did not show any individual to be homozygous Duffy negative.

\section{Discussion}

In contrast to the situation in other West African countries, $P$. vivax is a widely distributed cause of clinical malaria in Mauritania. Cases occur over a large area, and are not restricted to the capital Nouakchott from where they were previously described. Remarkably, there is no information on the occurrence of this parasite species in country malaria reports for Mauritania given by the World Health Organization [5]. This study shows that the species exists alongside $P$. falciparum in the central 
Table 2 Proportions of malaria infections containing P. vivax and P. falciparum at each of three health facilities sampled in Nouakchott, the capital of Mauritania

\begin{tabular}{|c|c|c|c|c|c|}
\hline $\begin{array}{l}\text { Health facility } \\
\text { and year of sampling }\end{array}$ & $\begin{array}{l}\text { Number of } \\
\text { cases sampled }\end{array}$ & P. vivax alone & $\begin{array}{l}\text { P. falciparum } \\
\text { alone }\end{array}$ & $\begin{array}{l}\text { P. vivax } \\
\text { and } P \text {. falciparum mixed }\end{array}$ & $\begin{array}{l}\text { Proportion of } P \text {. vivax } \\
(P v /[P v+P f])^{\mathrm{a}}\end{array}$ \\
\hline \multicolumn{6}{|l|}{2012} \\
\hline Teyarett Health Centre & 53 & 49 (92\%) & $4(8 \%)$ & 0 & 0.92 \\
\hline National Hospital Centre & 43 & $16(37 \%)$ & $16(37 \%)$ & $11(26 \%)$ & 0.50 \\
\hline \multicolumn{6}{|l|}{2013} \\
\hline Teyarett Health Centre & 73 & $62(85 \%)$ & $10(14 \%)$ & $1(1 \%)$ & 0.84 \\
\hline $\begin{array}{l}\text { Cheikh Zayed Hospital } \\
\text { Centre }\end{array}$ & 7 & $3(43 \%)$ & $4(57 \%)$ & 0 & 0.43 \\
\hline
\end{tabular}

a Relative proportions of each species at each hospital are estimated by counting numbers of infections with each species, with each being counted separately from mixed species infections

and southwest parts of the country (Tagant, Brakna and Assaba regions), and in Nouakchott where its relative frequency as a cause of malaria varies between different health facilities. Notably, $P$. vivax was the only parasite species seen in malaria patients from Zouérat in the north of the country (Tiris Zemmour region), whereas in the southeast of the country it is clear that $P$. falciparum dominates and $P$. vivax is rarely seen.

The epidemiology of malaria in these communities needs to be better understood. It is possible that $P$. vivax might be maintained in areas with minimal transmission in the centre and north of the country due to long persistence of infection in individuals experiencing occasional relapse from dormant hypnozoite stages in the liver. As samples were from individuals who had not reported travelling within the previous 2 weeks, most of the cases were probably acquired locally, although some might have been due to relapses of $P$. vivax infections acquired previously. A study of malaria in northern Senegal near the border with Mauritania surveyed households of index cases [20], revealing that many $P$. falciparum infections are associated with travel to more highly endemic parts of Senegal. Surveys based around index cases may also be useful to understand the epidemiology of $P$. vivax as well as $P$. falciparum in different parts of Mauritania. Although there is a previous report of a $P$. vivax-infected individual in Nouakchott who was Duffy negative [16], in the present study all cases of $P$. vivax tested were shown to be Duffy positive. Indeed, where $P$. vivax was seen to be clearly the predominant cause of malaria, for example in the Teyarett area of Nouakchott and in the northern town of Zouérat, most of the local population are white Maures, an ethnicity highly associated with Duffy positivity. Therefore, this parasite species will probably remain rare in the extreme south of Mauritania where most of the population are Duffy negative, but its widespread distribution in the central and northern parts of the country needs to be monitored and addressed.

Although the distributions of $P$. vivax and $P$. falciparum differ globally [21], it is remarkable that $P$. vivax as a widespread cause of malaria in communities living in desert and Sahel areas of West Africa has not been previously appreciated. The situation described here in Mauritania, and recent data on a limited number of positive samples in Senegal [22] and northern Mali [14, 15], suggest that $P$. vivax is likely to be endemic in many communities living in other parts of northwestern Africa which have yet to be surveyed with species-specific methods [2]. There is recent evidence suggesting that $P$. vivax emerged prehistorically as a zoonosis from African apes prior to becoming endemic in humans and then spreading to other continents [23]. It remains to be determined whether the current $P$. vivax distribution in Mauritania is part of a relict African parasite population, or whether the species was re-introduced in historical times.

\section{Conclusions}

Plasmodium vivax causes a substantial proportion of malaria cases in diverse parts of Mauritania. Far from being restricted to the capital Nouakchott, $P$. vivax is detected from five of the major administrative regions of this large country, including one northern town in which all cases sampled were caused by this species. This has significant implications for diagnosis, treatment and control of malaria in this part of northwest Africa, so reporting and advice by the World Health Organization and other authorities need to reflect the epidemiological situation.

\section{Authors' contributions}

$H B$ and DJC conceived and designed the study. HB, CWD, AAD, TBD, MYD, and AT collected the samples and performed laboratory assays. HB, CWD, AAD, and DJC performed data analysis and interpretation. HB and DJC wrote the manuscript. All authors read and approved the final manuscript. 


\section{Author details}

${ }^{1}$ Institut National de Recherches en Santé Publique (INRSP), Nouakchott, Mauritania. ${ }^{2}$ Department of Pathogen Molecular Biology, London School of Hygiene and Tropical Medicine, London, UK. ${ }^{3}$ Hôpital Le Dantec, Université Cheikh Anta Diop, Dakar, Senegal.

\section{Acknowledgements}

We are grateful to all patients, and staff of the health facilities for willing participation and support throughout the surveys. We acknowledge the support and encouragement of the Director Mohamed Brahim Elkory and other colleagues at the Institut National de Recherche en Santé Publique in Mauritania. We also thank Cyrille Diedhiou and Lindsay Stewart for laboratory support. This study received funding from the UK Medical Research Council (Project Grant G1100123).

\section{Competing interests}

The authors declare that they have no competing interests.

Received: 3 December 2015 Accepted: 22 January 2016

Published online: 09 February 2016

\section{References}

1. Gething PW, Patil AP, Smith DL, Guerra CA, Elyazar IR, Johnston GL, et al. A new world malaria map: Plasmodium falciparum endemicity in 2010. Malar J. 2011;10:378.

2. Howes RE, Reiner RC Jr, Battle KE, Longbottom J, Mappin B, Ordanovich $D$, et al. Plasmodium vivax transmission in Africa. PLoS Negl Trop Dis. 2015:9:e0004222.

3. Gething PW, Elyazar IR, Moyes CL, Smith DL, Battle KE, Guerra CA, et al. A long neglected world malaria map: Plasmodium vivax endemicity in 2010. PLoS Negl Trop Dis. 2012;6:e1814.

4. Bhatt S, Weiss DJ, Cameron E, Bisanzio D, Mappin B, Dalrymple U, et al. The effect of malaria control on Plasmodium falciparum in Africa between 2000 and 2015. Nature. 2015;526:207-11.

5. WHO. World Malaria Report 2015. Geneva: World Health Organization; 2015. http://www.who.int/malaria/publications/ world-malaria-report-2015/report/en/

6. Ceesay SJ, Casals-Pascual C, Nwakanma DC, Walther M, Gomez-Escobar N, Fulford AJ, et al. Continued decline of malaria in the Gambia with implications for elimination. PLOS ONE. 2010;5:e12242.

7. Trape JF, Sauvage C, Ndiaye O, Douillot L, Marra A, Diallo A, et al. New malaria-control policies and child mortality in Senegal: reaching millennium development goal 4. J Infect Dis. 2012;205:672-9.

8. Lekwiry KM, Ould Ahmadou Salem MS, Basco LK, Briolant S, Hafid J, Ould Mohamed Salem Boukhary A. Malaria in Mauritania: retrospective and prospective overview. Malar J. 2015;14:100
9. Lekweiry KM, Abdallahi MO, Ba H, Arnathau C, Durand P, Trape JF, et al. Preliminary study of malaria incidence in Nouakchott, Mauritania. Malar J. 2009;8:92.

10. Lekweiry KM, Basco LK, Salem MS, Hafid JE, Marin-Jauffre A, Weddih AO, et al. Malaria prevalence and morbidity among children reporting at health facilities in Nouakchott, Mauritania. Trans R Soc Trop Med Hyg. 2011;105:727-33.

11. Cortes H, Morillas-Marquez F, Valero A. Malaria in Mauritania: the first cases of malaria endemic to Nouakchott. Trop Med Int Health. 2003:8:297-300.

12. Ould Ahmedou Salem MS, Mint Lekweiry K, Mint Deida J, Ould Emouh A, Ould Weddady M, Ould Mohamed Salem Boukhary MS, et al. Increasing prevalence of Plasmodium vivax among febrile patients in Nouakchott. Mauritania. Am J Trop Med Hyg. 2015;92:537-40.

13. Culleton RL, Mita T, Ndounga M, Unger H, Cravo PV, Paganotti GM, et al. Failure to detect Plasmodium vivax in West and Central Africa by PCR species typing. Malar J. 2008;7:174.

14. Bernabeu M, Gomez-Perez GP, Sissoko S, Niambele MB, Haibala AA, Sanz $A$, et al. Plasmodium vivax malaria in Mali: a study from three different regions. Malar J. 2012;11:405.

15. Koita OA, Sangare L, Sango HA, Dao S, Keita N, Maiga M, et al. Effect of seasonality and ecological factors on the prevalence of the four malaria parasite species in northern Mali. J Trop Med. 2012;2012:367160.

16. Wurtz N, Mint Lekweiry K, Bogreau H, Pradines B, Rogier C, Ould Mohamed Salem Boukhary A, et al. Vivax malaria in Mauritania includes infection of a Duffy-negative individual. Malar J. 2011;10:336.

17. Ould Ahmedou Salem MS, Basco LK, Ouldabdallahi M, Mint Lekweiry K, Konate L, Faye $\mathrm{O}$, et al. Malaria-associated morbidity during the rainy season in Saharan and Sahelian zones in Mauritania. Acta Trop. 2015;152:1-7.

18. Snounou G, Viriyakosol S, Zhu XP, Jarra W, Pinheiro L, do Rosario VE, et al. High sensitivity of detection of human malaria parasites by the use of nested polymerase chain reaction. Mol Biochem Parasitol. 1993;61:315-20.

19. Zimmerman PA, Woolley I, Masinde GL, Miller SM, McNamara DT, Hazlett $F$, et al. Emergence of $F Y^{*} A(n u l l)$ in a Plasmodium vivax-endemic region of Papua New Guinea. Proc Natl Acad Sci U S A. 1999;96:13973-7.

20. Littrell M, Sow GD, Ngom A, Ba M, Mboup BM, Dieye Y, et al. Case investigation and reactive case detection for malaria elimination in northern Senegal. Malar J. 2013;12:331.

21. Dalrymple U, Mappin B, Gething PW. Malaria mapping: understanding the global endemicity of falciparum and vivax malaria. BMC Med. 2015;13:140.

22. Niang M, Thiam LG, Sow A, Loucoubar C, Bob NS, Diop F, et al. A molecular survey of acute febrile illnesses reveals Plasmodium vivax infections in Kedougou, southeastern Senegal. Malar J. 2015;14:281.

23. Liu W, Li Y, Shaw KS, Learn GH, Plenderleith L, Malenke JA, et al. African origin of the malaria parasite Plasmodium vivax. Nat Commun. 2014;5:3346.

\section{Submit your next manuscript to BioMed Central and we will help you at every step:}

- We accept pre-submission inquiries

- Our selector tool helps you to find the most relevant journal

- We provide round the clock customer support

- Convenient online submission

- Thorough peer review

- Inclusion in PubMed and all major indexing services

- Maximum visibility for your research

Submit your manuscript at www.biomedcentral.com/submit

C Biomed Central 